\title{
Investigating Variations in Water Abundances in Lunar Felsite Clasts Using Coordinated Field-Emission STEM and NanoSIMS Analyses
}

\author{
Roy Christoffersen ${ }^{1}$, Justin I. Simon ${ }^{2}$, Megan D. Mouser ${ }^{3}$, Zia Rahman $^{1}$ \\ ${ }^{1}$ Jacobs, NASA Johnson Space Center, Mail Code XI3, Houston, USA. \\ ${ }^{2}$ Center for Isotope Cosmochemistry and Geochronology, Astromaterials Research \& Exploration \\ Science, NASA Johnson Space Center, Houston, USA. \\ ${ }^{3}$ Dept. of Earth and Planetary Sciences, University of Tennessee, Knoxville, USA.
}

As representatives of petrochemically evolved igneous rocks on the Moon, the granitic felsite clasts in lunar breccias have come under renewed focus as part of new efforts to use feldspars for assessing the inventory of lunar water and other volatiles [1,2]. Previous petrologic studies of these clasts $[3,4]$ were tilted towards finding those assemblages and relationships most likely to be direct products of magmatic processes. In support of our on-going NanoSIMS measurements of trace water contents in the feldspars in these clasts [1,2], we are using coordinated analytical SEM, electron probe microanalyzer (EPMA) and analytical field emission scanning transmission electron microscopy (FE-STEM) techniques to reevaluate the full diversity of processes under which the feldspar-bearing assemblages in these clasts formed. Here we report a comparison of FE-STEM imaging and microanalysis results obtained on focused ion beam (FIB) sections extracted from felsite (alkali feldspar $+\mathrm{SiO}_{2} \pm$ plagioclase) clasts in lunar breccias 15405 and 12013. The feldspars in these clasts have water contents which, although relatively low (7-18 ppm) by terrestrial standards, still show values significantly higher than measurements $(\sim 0.5$ ppm) of nominally anhydrous NanoSIMS standards.

Using an FEI Quanta dual-beam FIB, we extracted FIB sections adjacent to regions in felsite clasts from 15405 and 12013 where we have previously made NanoSIMS analyses of trace water contents in both alkali feldspar and plagioclase [1,2]. Prior to FIB sectioning, the clast mineralogy, mineral composition and microstructure was characterized using a JEOL 7600F field-emission SEM and a JEOL 8530F fieldemission EPMA, both with energy-dispersive X-ray (EDS) element mapping capabilities. The FIB sections where characterized using a JEOL 7600 FE-STEM optimized for X-ray EDS compositional spectrum imaging.

Feldspars in the 15405 and 12013 felsite are complexly intergrown with a silica phase in microstructurally distinct assemblages known as microgranophyres. In the 15405 microgranophyres (Fig. 1), the feldspathic part of the intergrowth has a nominal Ca-rich K-feldspar composition that EPMA analyses showed is nevertheless alkali cation deficient relative to normal stoichiometry. FESTEM characterization confirmed the feldspathic regions to be wholly glassy, while the silica phase was the $\mathrm{SiO}_{2}$ polymorph tridymite (Fig. 1b,c). The tridymite exhibits a high density of planar defects that are either transformation twins or stacking faults (Fig. 1c). It forms intergrown laths, but also occurs as crystallites within the feldspathic glass that are either quench crystals or incompletely melted larger grains (Fig. 1b). The 15405 microgranophyre has an overall microstructure similar to other lunar microgranophyres that are wholly crystalline with stoichiometric feldspars. On the FE-STEM scale, however, the evidence suggests the originally crystalline clast was subjected to a re-heating event, possibly associated with shock effects, that melted the feldspar, causing alkali cation loss, ultimately stabilizing tridymite $\left(>900^{\circ} \mathrm{C}\right)$. Compared to the 15405 sample, FE-STEM characterization of the 12013 microgranophyre (Fig. 2), confirms that the silica phase is $\alpha$-quartz and the feldspar is a wholly 
crystalline, stoichiometric Ca-rich K-feldspar (Fig. 2b,c). FE-STEM imaging also confirmed that plagioclase-K-feldspar intergrowths associated with the microgranophyre, for which water contents were also measured, are wholly crystalline but with numerous low-angle subgrain boundaries, suggesting recovery from a strain event, likely also due to shock.

Our NanoSIMS data showed an 18 ppm water content in the glassy 15405 assemblage that is in same range as the 15-7 ppm values measured in the less deformed 12013 sample. The fact that the 15405 sample retained water after being significantly re-processed may be due to the short duration of the shock/thermal disturbance, or to the possibility that the disturbance itself may have added water (i.e., hydrous impact event causing shock melting and possibly formation of the host breccia).

References:

[1] R. D. Mills et al, Geochem. Persp. Let. 3 (2017), p. 115.

[2] J. I. Simon et al, Lunar and Planetary Science Conference XLVIII (2017), Abstract \#1248.

[3] S. M. Seddio et al, Am. Min. 100 (2015), p. 1533.

[4] J. E. Quick et al, Proc. Lunar Planet. Sci. 12B (1981), p. 117.
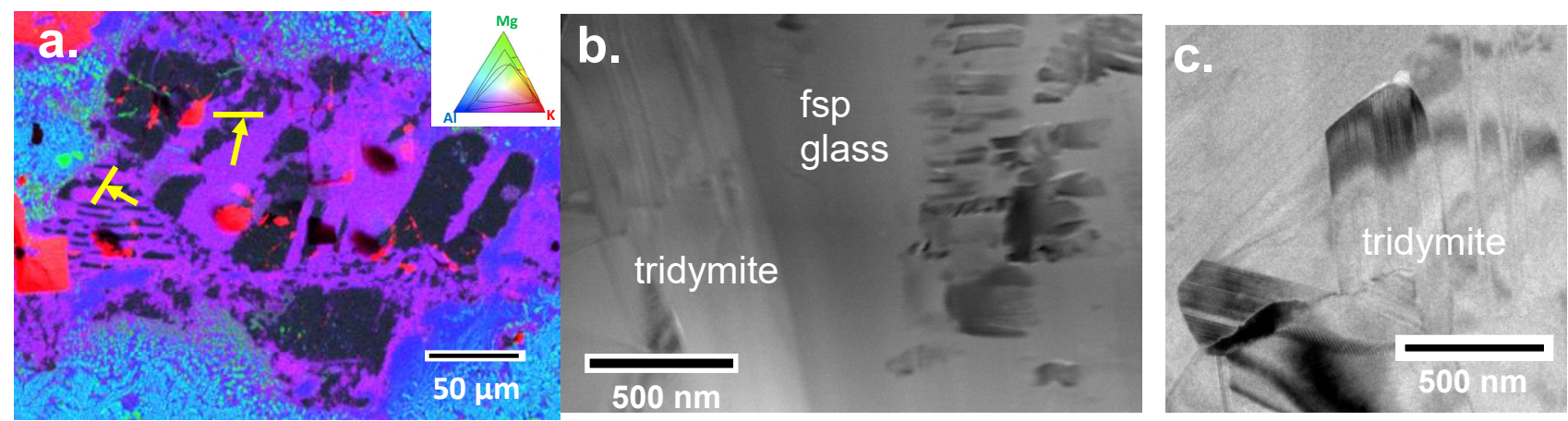

Figure 1. (a) SEM EDS element map of 15045 microgranophyre, with FIB sections shown by arrows. $(b, c)$ Conventional TEM bright-field image of glassy feldspathic region with tridymite.
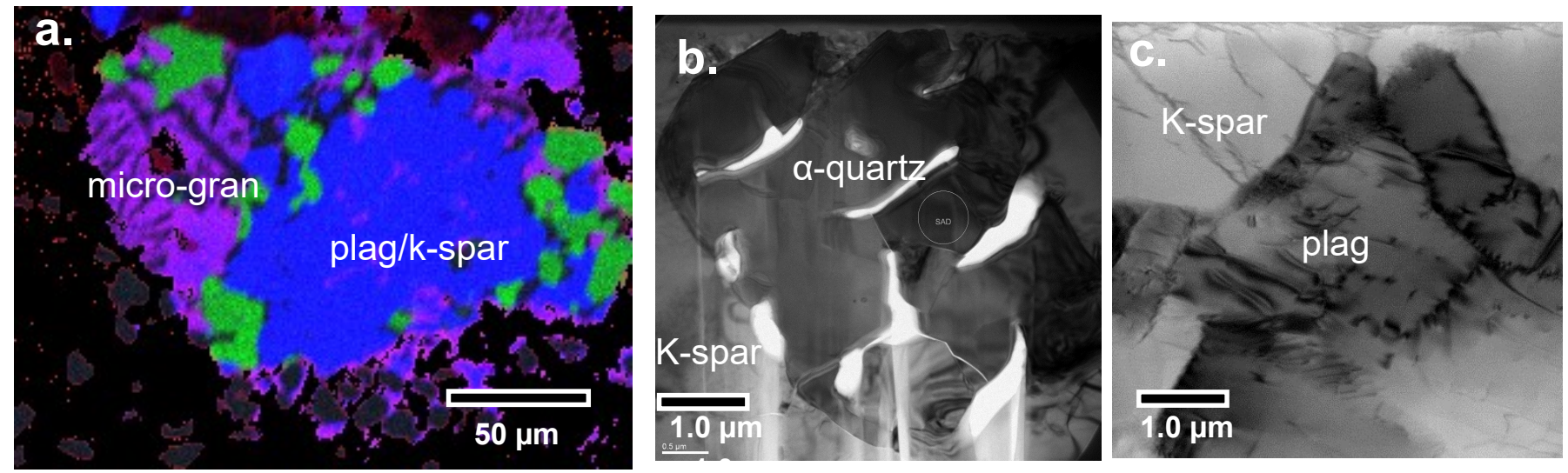

Figure 2. (a) SEM EDS element map of 12013 microgranophyre and adjacent K-feldspar/plagioclase intergrowth, (b) conventional TEM bright-field image of $\alpha$-quartz and K-feldspar in microgranophyre, (c) conventional TEM bright-field image of plagioclase/K-feldspar intergrowth. 